\title{
Non-invasive ventilation versus high-flow nasal oxygen for postextubation respiratory failure in ICU: a post-hoc analysis of a randomized clinical trial
}

\author{
Arnaud W. Thille ${ }^{1,2^{*}} \mathbb{0}$, Grégoire Monseau', Rémi Coudroy ${ }^{1,2}$, Mai-Anh Nay $^{3}$, Arnaud Gacouin 4 , \\ Maxens Decavèle ${ }^{5}$, Romain Sonneville ${ }^{6}$, François Beloncle ${ }^{7}$, Christophe Girault ${ }^{8}$, Laurence Dangers ${ }^{9}$, \\ Alexandre Lautrette ${ }^{10}$, Quentin Levrat ${ }^{11}$, Anahita Rouzé ${ }^{12}$, Emmanuel Vivier ${ }^{13}$, Jean-Baptiste Lascarrou ${ }^{14}$, \\ Jean-Damien Ricard ${ }^{15}$, Keyvan Razazi ${ }^{16}$, Guillaume Barberet ${ }^{17}{ }^{17}$ Christine Lebert $^{18}$, Stephan Ehrmann ${ }^{19}$, \\ Alexandre Massri ${ }^{20}$, Jeremy Bourenne ${ }^{21}$, Gael Pradel ${ }^{22}$, Pierre Bailly ${ }^{23}$, Nicolas Terzi ${ }^{24}$, Jean Dellamonica ${ }^{25}$, \\ Guillaume Lacave ${ }^{26}$, René Robert ${ }^{1,2}$, Stéphanie Ragot ${ }^{2}$ and Jean-Pierre Frat ${ }^{1,2}$ for the HIGH-WEAN Study Group \\ and the REVA research network
}

\begin{abstract}
Background: In intensive care units (ICUs), patients experiencing post-extubation respiratory failure have poor outcomes. The use of noninvasive ventilation (NIV) to treat post-extubation respiratory failure may increase the risk of death. This study aims at comparing mortality between patients treated with NIV alternating with high-flow nasal oxygen or high-flow nasal oxygen alone.

Methods: Post-hoc analysis of a multicenter, randomized, controlled trial focusing on patients who experienced post-extubation respiratory failure within the 7 days following extubation. Patients were classified in the NIV group or the high-flow nasal oxygen group according to oxygenation strategy used after the onset of post-extubation respiratory failure. Patients reintubated within the first hour after extubation and those promptly reintubated without prior treatment were excluded. The primary outcome was mortality at day 28 after the onset of post-extubation respiratory failure.

Results: Among 651 extubated patients, 158 (25\%) experienced respiratory failure and 146 were included in the analysis. Mortality at day 28 was 18\% (15/84) using NIV alternating with high-flow nasal oxygen and 29\% (18/62) with high flow nasal oxygen alone (difference, $-11 \%[95 \% \mathrm{Cl},-25$ to 2$] ; p=0.12$ ). Among the 46 patients with hypercapnia at the onset of respiratory failure, mortality at day 28 was 3\% (1/33) with NIV and 31\% (4/13) with high-flow nasal oxygen alone (difference, $-28 \%[95 \% \mathrm{Cl},-54$ to -6$] ; p=0.006$ ). The proportion of patients reintubated $48 \mathrm{~h}$ after the onset of post-extubation respiratory failure was 44\% (37/84) with NIV and 52\% (32/62) with high-flow nasal oxygen alone $(p=0.21)$.
\end{abstract}

\footnotetext{
*Correspondence: aw.thille@gmail.com

1 Centre Hospitalier Universitaire de Poitiers, Service de Médecine

Intensive Réanimation, Médecine Intensive Réanimation, 2 rue la Milétrie,

86021 Poitiers Cedex, France

Full list of author information is available at the end of the article
}

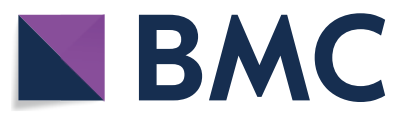

(c) The Author(s) 2021. Open Access This article is licensed under a Creative Commons Attribution 4.0 International License, which permits use, sharing, adaptation, distribution and reproduction in any medium or format, as long as you give appropriate credit to the original author(s) and the source, provide a link to the Creative Commons licence, and indicate if changes were made. The images or other third party material in this article are included in the article's Creative Commons licence, unless indicated otherwise in a credit line to the material. If material is not included in the article's Creative Commons licence and your intended use is not permitted by statutory regulation or exceeds the permitted use, you will need to obtain permission directly from the copyright holder. To view a copy of this licence, visit http://creativecommons.org/licenses/by/4.0/. The Creative Commons Public Domain Dedication waiver (http://creativeco mmons.org/publicdomain/zero/1.0/) applies to the data made available in this article, unless otherwise stated in a credit line to the data. 
Conclusions: In patients with post-extubation respiratory failure, NIV alternating with high-flow nasal oxygen might not increase the risk of death.

Trial registration number

The trial was registered at http://www.clinicaltrials.gov with the registration number NCT03121482 the 20th April 2017.

Keywords: Airway extubation, Ventilator weaning, Acute respiratory failure, Noninvasive ventilation, High-flow nasal oxygen

\section{Background}

In ICUs, around 20 to $30 \%$ of patients experience an episode of respiratory failure after extubation, although at the time of the decision to extubate they met all the usual criteria to be successfully separated from the ventilator $[1,2]$. Nearly half of them eventually require reintubation with subsequently high mortality rates reaching $30-40 \%$ [1-5]. Consequently, an oxygenation strategy aimed at avoiding reintubation deserves consideration.

Prophylactic use of non-invasive ventilation (NIV) applied immediately after extubation may prevent postextubation respiratory failure [1, 6-9]. By contrast, NIV used as rescue therapy to treat post-extubation respiratory failure could increase the risk of death by delaying reintubation [10]. The largest clinical trial conducted to date showed greater mortality with NIV than with standard oxygen even though reintubation rates were exactly the same [10]. The only difference explaining the deleterious effects of NIV was that the intubation delay was markedly longer than with standard oxygen. Thereby, the most recent international clinical practice guidelines suggest that NIV should not be used in the treatment of patients with established post-extubation respiratory failure [11]. However, NIV as rescue therapy may avoid reintubation in a number of cases, especially in hypercapnic patients with underlying chronic lung disease $[7,8$, $12,13]$, and recent large-scale clinical trials have shown that around 30 to $40 \%$ of patients with post-extubation respiratory failure are actually treated with $\operatorname{NIV}[1,2]$. High-flow nasal oxygen is increasingly used after extubation in order to prevent post-extubation respiratory failure [14-16], and could be used in case of post-extubation respiratory failure. Although its beneficial effects have been reported in treatment of acute respiratory failure [17], high-flow nasal oxygen has never been specifically studied for management of post-extubation respiratory failure, and the best oxygenation strategy in this setting remains unknown.

We recently conducted a randomized controlled trial showing that prophylactic use of NIV alternating with high-flow nasal oxygen immediately after extubation significantly decreased the risk of post-extubation respiratory failure as compared to high-flow nasal oxygen alone
[1]. Based on this trial, we conducted a post-hoc analysis aimed at comparing the effects of NIV alternating with high-flow nasal oxygen vs. high-flow nasal oxygen alone on reintubation and mortality among patients experiencing post-extubation respiratory failure. We also aimed to compare reintubation rates and to identify risk factors associated with reintubation.

\section{Methods \\ Study design and patients}

Post-hoc analysis of a multicenter, randomized, controlled trial comparing prophylactic use of NIV alternating with high-flow nasal oxygen (i.e. NIV interspaced with high-flow nasal oxygen between NIV sessions) versus high-flow nasal oxygen alone immediately after extubation in 641 patients at high-risk of extubation failure in ICUs [1]. The present analysis focused on patients who experienced respiratory failure within the 7 days following extubation. Post-extubation respiratory failure was prospectively collected and was defined by the presence of at least two criteria among the following: respiratory rate $>25$ breaths per minute, clinical signs suggesting respiratory distress, respiratory acidosis defined as $\mathrm{pH}<7.35$ units and $\mathrm{PaCO}_{2}>45 \mathrm{~mm} \mathrm{Hg}$, and hypoxemia defined as $\mathrm{FiO}_{2} \geq 50 \%$ to maintain $\mathrm{SpO}_{2} \geq 92 \%$ or a $\mathrm{PaO}_{2} /$ $\mathrm{FiO}_{2} \leq 150 \mathrm{~mm} \mathrm{Hg}$. Hypoxemia was assessed using arterial blood gases performed at one hour, six hours, between 12 and $24 \mathrm{~h}$ and between 24 and $48 \mathrm{~h}$ following extubation, and then once a day until ICU discharge. For patients under standard oxygen, $\mathrm{FiO}_{2}$ was calculated according to the following formula: $\mathrm{FiO}_{2}=0.21+0.03$ per supplemental litre of oxygen [18].

Patients reintubated within the first hour after extubation and those who were promptly reintubated without prior specific treatment (i.e., who did not receive neither NIV nor high-flow nasal oxygen between the onset of respiratory failure and reintubation) were not retained in the analysis.

The original study was approved by the independent ethics committee of Poitiers (Ethics Committee Ouest III, Poitiers, France). Written informed consent was obtained from all patients or next of kin before inclusion. 


\section{Treatment groups}

The choice of oxygenation strategy to treat post-extubation respiratory failure was left to the physician's decision. Patients in whom NIV was continued or initiated after the onset of post-extubation respiratory failure were classified in the NIV group. Patients who were treated with high-flow nasal oxygen alone after onset of postextubation respiratory failure were classified in the highflow nasal oxygen group. If the decision was to use NIV, it was recommended to use a minimal pressure-support level of $5 \mathrm{~cm} \mathrm{H}_{2} \mathrm{O}$ targeting a tidal volume around 6 to $8 \mathrm{ml} / \mathrm{kg}$ of predicted body weight, a positive end-expiratory pressure (PEEP) level between 5 and $10 \mathrm{cmH}_{2} \mathrm{O}$ and a fraction of inspired oxygen $\left(\mathrm{FiO}_{2}\right)$ adjusted to obtain adequate oxygenation $\left(\mathrm{SpO}_{2} \geq 92 \%\right)$. If the decision was to use high-flow nasal oxygen, it was recommended to deliver a flow rate of $50 \mathrm{~L} / \mathrm{min}$ and $\mathrm{FiO}_{2}$ adjusted to obtain adequate oxygenation $\left(\mathrm{SpO}_{2} \geq 92 \%\right)$.

\section{Outcomes}

The main outcome was mortality rates within the 28 days after the onset of post-extubation respiratory failure according to oxygenation strategy. Although reintubation within the 7 days following extubation was the primary outcome in the original study [1], we decided to choose mortality as primary outcome rather than reintubation given NIV could be associated with an increased risk of death without increased risk of reintubation compared with oxygen [10].

Secondary outcomes included reintubation rates within the first $48 \mathrm{~h}$ after the onset of respiratory failure and up until ICU discharge, the interval between the onset of respiratory failure and reintubation, length of stay in the ICU, mortality in the ICU and within 90 days following extubation. Severe respiratory failure leading to reintubation was defined by the presence of at least two criteria among the following: respiratory rate $>35$ breaths per minute, clinical signs suggesting respiratory distress, respiratory acidosis defined as $\mathrm{pH}<7.25$ units and $\mathrm{PaCO}_{2}>45 \mathrm{~mm} \mathrm{Hg}$, hypoxemia defined as $\mathrm{FiO}_{2} \geq 80 \%$ to maintain $\mathrm{SpO}_{2} \geq 92 \%$ or a $\mathrm{PaO}_{2} / \mathrm{FiO}_{2} \leq 100 \mathrm{~mm} \mathrm{Hg}$.

\section{Statistical analysis}

Continuous variables were expressed as mean \pm standard deviation (SD) or median [interquartile range, IQR 25th-75th percentiles], and qualitative variables were expressed as number and percentage.

Mortality rates within the 28 days following postextubation respiratory failure were compared between the NIV group and the high-flow nasal oxygen group by means of the $x^{2}$ test. Kaplan-Meier curves were plotted to assess the time from the onset of post-extubation respiratory failure to death and were compared by means of the log-rank test at day 28 . As the effect of oxygenation strategy on mortality may be different according to $\mathrm{PaCO}_{2}$ level [7], a subgroup analysis was performed in patients with hypercapnia at the onset of respiratory failure (defined as $\mathrm{PaCO}_{2}>45 \mathrm{~mm} \mathrm{Hg}$ ).

Secondary outcomes including reintubation rates were compared between the 2 groups by means of the $x^{2}$ tests or Fisher exact test for categorical variables and Student's $t$-test or Wilcoxon test for continuous variables as appropriate. Kaplan-Meier curves were plotted to assess time from the onset of post-extubation respiratory failure to reintubation and were compared by means of the logrank test at $48 \mathrm{~h}$. A multiple logistic regression analysis was performed for reintubation in ICU with the use of a backward-selection procedure. All variables associated with reintubation with a $p$ value of less than 0.20 after univariate analysis were entered into the maximal model. The results were presented as odds ratio (OR) with 95\% confidence interval (95CI). A two-tailed $\mathrm{p}$ value of less than 0.05 was considered statistically significant. We used SAS software, version 9.4 (SAS Institute), for all the analyses.

\section{Result}

Among the 651 patients extubated in the 30 participating ICUs, 158 (25\%) experienced respiratory failure within the 7 days following extubation. After excluding 1 patient with missing data, 4 patients who were reintubated within the first hour after extubation, and 7 patients who were promptly reintubated without prior treatment by high-flow nasal oxygen or NIV, 146 patients with postextubation respiratory failure were retained in the analysis including 84 patients treated with NIV alternating with high-flow nasal oxygen and 62 patients treated with high-flow nasal oxygen alone (Table 1). Interval between extubation and respiratory failure did not differ between the 2 groups $(22 \mathrm{~h}$ in median in the NIV group [IQR $4-57$ ] vs. $20 \mathrm{~h}$ in the high-flow oxygen group [IQR 5-47], $p=0.89$ ). Among the 123 patients in whom blood gas measurement was obtained at the onset of post-extubation respiratory failure, 46 patients $(37 \%)$ had hypercapnia. NIV was more frequently used in patients who had hypercapnia at time of post-extubation respiratory failure and in those who had already received NIV as preventive measure before the onset of respiratory failure.

Ventilator settings used for the treatment of postextubation respiratory failure using NIV were the following: a pressure-support level of $8 \pm 3 \mathrm{~cm} \mathrm{H}_{2} \mathrm{O}$, a PEEP level of $5 \pm 1 \mathrm{~cm} \mathrm{H}_{2} \mathrm{O}$, and $\mathrm{FiO}_{2}$ of $0.45 \pm 0.16$, resulting in a tidal volume of $8 \pm 2 \mathrm{ml}$ per kilogram of predicted body weight. Patients treated with high-flow 
Table 1 Comparison of patients treated with high-flow nasal oxygen alone and those treated with non-invasive ventilation (NIV) for post-extubation respiratory failure

\begin{tabular}{|c|c|c|c|}
\hline & $\begin{array}{l}\text { High-flow nasal oxygen } \\
(n=62)\end{array}$ & $\begin{array}{l}\text { Non-invasive ventilation } \\
(n=84)\end{array}$ & $P$ value \\
\hline \multicolumn{4}{|l|}{ Characteristics of the patients at admission } \\
\hline Age, years & $71 \pm 9$ & $70 \pm 9$ & 0.59 \\
\hline Male sex, n (\%) & $40(65 \%)$ & $53(63 \%)$ & 0.86 \\
\hline Body-mass index, $\mathrm{kg} / \mathrm{m}^{2}$ & $29 \pm 7$ & $28 \pm 7$ & 0.91 \\
\hline SAPS II at admission, points & $60 \pm 18$ & $56 \pm 17$ & 0.22 \\
\hline Underlying chronic cardiac disease, $\mathrm{n}(\%)$ & $27(44 \%)$ & $38(45 \%)$ & 0.84 \\
\hline Underlying chronic lung disease, n (\%) & $23(37 \%)$ & $34(40 \%)$ & 0.68 \\
\hline Chronic obstructive pulmonary disease, $\mathrm{n}(\%)$ & $18(29 \%)$ & $25(30 \%)$ & 0.92 \\
\hline Acute respiratory failure as reason for intubation, n (\%) & $35(56 \%)$ & $54(64 \%)$ & 0.34 \\
\hline \multicolumn{4}{|l|}{ Characteristics of the patients the day of extubation } \\
\hline SOFA score, points & $4.5 \pm 2.7$ & $4.4 \pm 2.8$ & 0.84 \\
\hline Duration of mechanical ventilation, median (IQR), days & $5[3-11]$ & $6[4-10]$ & 0.71 \\
\hline Weaning difficulty ${ }^{\mathrm{a}}, \mathrm{n}(\%)$ & & & 0.20 \\
\hline -Simple weaning & $36(58 \%)$ & $49(58 \%)$ & \\
\hline -Difficult or prolonged weaning & $26(42 \%)$ & $35(42 \%)$ & \\
\hline Ineffective cough, n/n total (\%) & $15 / 58(26 \%)$ & $31 / 82(38 \%)$ & 0,14 \\
\hline Abundant secretions, n/n total (\%) & $30 / 57(53 \%)$ & $32 / 83(39 \%)$ & 0,10 \\
\hline Administration of steroids before extubation, $\mathrm{n}(\%)$ & $4(6 \%)$ & $13(15 \%)$ & 0,09 \\
\hline Prophylactic NIV after extubation, n (\%) & $7(11 \%)$ & $56(67 \%)$ & $<0.001$ \\
\hline \multicolumn{4}{|l|}{ Characteristics at time of respiratory failure } \\
\hline Interval between extubation and respiratory failure, hours & $20[5-47]$ & $22[4-57]$ & 0.89 \\
\hline Systolic arterial pressure, $\mathrm{mm} \mathrm{Hg}$ & $136 \pm 21$ & $135 \pm 26$ & 0.82 \\
\hline Diastolic arterial pressure, $\mathrm{mm} \mathrm{Hg}$ & $67 \pm 13$ & $66 \pm 16$ & 0.68 \\
\hline Heart rate, beats/min & $90 \pm 28$ & $87 \pm 35$ & 0.58 \\
\hline Respiratory rate, breaths/min & 27 [23-33] & $30[25-37]$ & 0.07 \\
\hline Clinical signs suggesting respiratory distress, n (\%) & $20(32 \%)$ & $33(39 \%)$ & 0.38 \\
\hline $\mathrm{SpO}_{2}, \%$ & $94 \pm 7$ & $95 \pm 4$ & 0.40 \\
\hline $\mathrm{PaO}_{2}, \mathrm{~mm} \mathrm{Hg}$ & $83 \pm 39$ & $80 \pm 24$ & 0.66 \\
\hline $\mathrm{PaO}_{2} / \mathrm{FiO}_{2}, \mathrm{~mm} \mathrm{Hg}$ & $181 \pm 72$ & $187 \pm 76$ & 0.70 \\
\hline $\mathrm{pH}$, units & $7.46 \pm 0.06$ & $7.41 \pm 0.10$ & $<0.01$ \\
\hline $\mathrm{PaCO}_{2}, \mathrm{~mm} \mathrm{Hg}$ & $41 \pm 9$ & $48 \pm 17$ & $<0.01$ \\
\hline Hypercapnia $\left(\mathrm{PaCO}_{2}>45 \mathrm{~mm} \mathrm{Hg}\right), \mathrm{n} / \mathrm{n}$ total $(\%)$ & $13 / 50(26 \%)$ & $33 / 73(45 \%)$ & 0.03 \\
\hline \multicolumn{4}{|c|}{ Treatment duration between the onset of respiratory failure and recovery or reintubation, hours } \\
\hline Duration of high-flow nasal oxygen, hours & $14[2-54]$ & $10[1-33]$ & 0.04 \\
\hline Duration of NIV, hours & $0[0-0]$ & $12[4-27]$ & $<0.001$ \\
\hline
\end{tabular}

$P$ values indicated in bold were considered statistically significant $(P<0.05)$

Continuous variables are given in mean \pm standard deviation or median [interquartile range, IQR 25th-75th percentiles] according to their distribution

SAPS = Simplified Acute Physiology Score; SOFA = Sepsis-related Organ Failure Assessment; NIV = Non-Invasive Ventilation

${ }^{a}$ Weaning difficulty was defined as follows: simple weaning included patients extubated after success of the initial spontaneous breathing trial, difficult weaning included patients who failed the initial spontaneous breathing trial and were extubated within the 7 following days, and prolonged weaning included patients extubated more than 7 days after the initial spontaneous breathing trial

nasal oxygen alone received a gas flow rate of $50 \pm 5 \mathrm{~L} /$ min with $\mathrm{FiO}_{2}$ of approximately $0.49 \pm 0.16$.

After the onset of post-extubation respiratory failure and until reintubation or recovery, NIV was delivered for a median of $12 \mathrm{~h}$ [IQR 4-27] and high-flow nasal oxygen for $10 \mathrm{~h}$ ([IQR 1-33] between NIV sessions in the NIV group. High-flow nasal oxygen was delivered for $14 \mathrm{~h}$ [IQR 2-54] in the high-flow nasal oxygen group. 
Table 2 Comparison of outcomes between patients treated with high-flow nasal oxygen alone and those treated with non-invasive ventilation for post-extubation respiratory failure

\begin{tabular}{|c|c|c|c|c|}
\hline & $\begin{array}{l}\text { High-flow nasal oxygen } \\
(n=62)\end{array}$ & $\begin{array}{l}\text { Non-invasive ventilation } \\
(n=84)\end{array}$ & $\begin{array}{l}\text { Absolute difference, } \% \\
(95 \% \mathrm{Cl})\end{array}$ & $P$ value \\
\hline \multicolumn{5}{|l|}{ Primary outcome } \\
\hline Mortality at day $28, \mathrm{n}(\%)$ & $18(29 \%)$ & $15(18 \%)$ & -11 ( -25 to 2$)$ & 0.11 \\
\hline \multicolumn{5}{|l|}{ Secondary outcomes } \\
\hline Reintubation at 48 h, n (\%) & $32(52 \%)$ & $37(44 \%)$ & -7 ( -23 to 9$)$ & 0.37 \\
\hline Reintubation up until ICU discharge, $\mathrm{n}(\%)$ & $35(56 \%)$ & $40(48 \%)$ & $-9(-24$ to 7$)$ & 0.29 \\
\hline Mortality of reintubated patients, n (\%) & $11 / 35(31 \%)$ & $12 / 40(30 \%)$ & -1 ( -22 to 19$)$ & 0.89 \\
\hline $\begin{array}{l}\text { Interval between the onset of respiratory failure and } \\
\text { reintubation, hours }\end{array}$ & $3.0[1.3-10.5]$ & $5.1[1.8-18.0]$ & - & 0.17 \\
\hline Length of stay in ICU, days & $8[4-14]$ & $8[5-17]$ & - & 0.48 \\
\hline Mortality in ICU, n (\%) & $14(23 \%)$ & $16(19 \%)$ & $-4(-17$ to 9$)$ & 0.60 \\
\hline Mortality at day 90, n (\%) & $24(39 \%)$ & $26(31 \%)$ & $-8(-23$ to 8$)$ & 0.33 \\
\hline
\end{tabular}

Continuous variables are given in mean \pm standard deviation or median [interquartile range, IQR 25 th-75th percentiles] according to their distribution

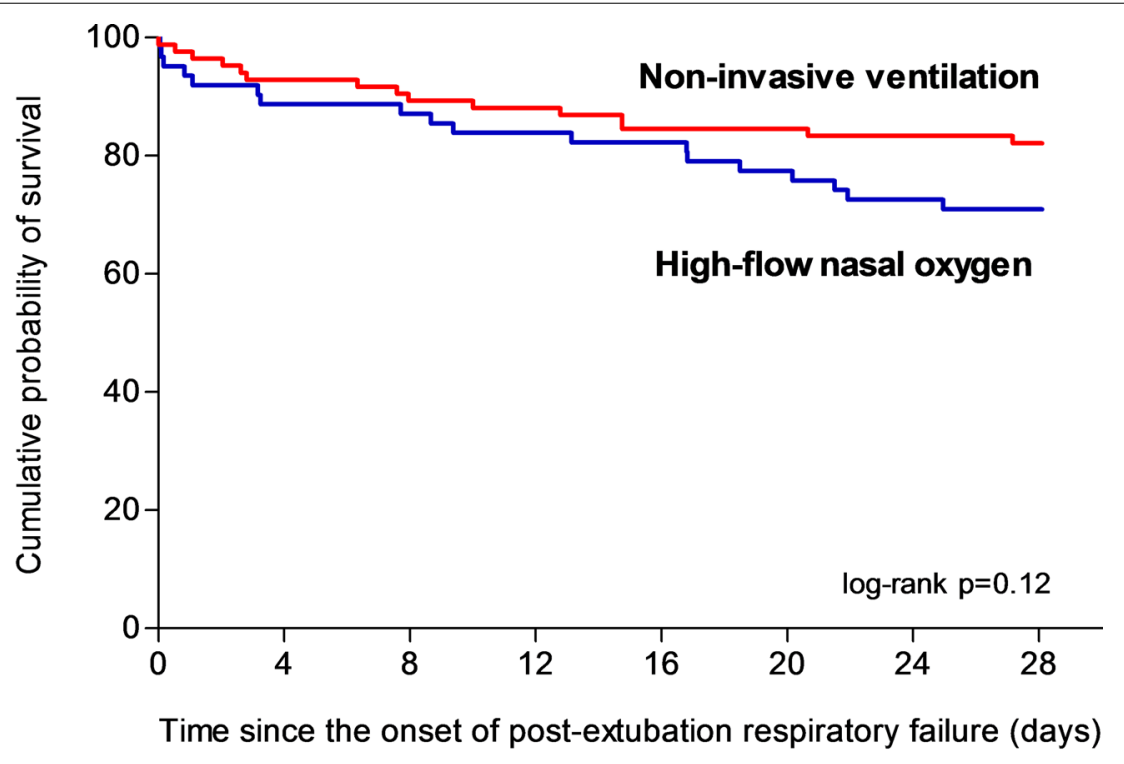

Number at risk

$\begin{array}{lllllllll}\text { High flow nasal oxygen } & 62 & 55 & 54 & 52 & 51 & 48 & 45 & 44 \\ \text { Non-invasive ventilation } & 84 & 78 & 75 & 74 & 71 & 71 & 70 & 69\end{array}$

Fig. 1 Kaplan-Meier analysis of time from the onset of post-extubation respiratory failure to death according to oxygenation strategy. Mortality rates at day 28 did not significantly differ between patients treated with high-flow nasal oxygen alone (blue line) and those treated with non-invasive ventilation (red line). Mortality at day 28 was 18\% (15 out of 84 patients) with NIV and 29\% (18 out of 62 patients) with high-flow nasal oxygen (difference, $-11 \%[95 \% \mathrm{Cl},-25$ to 2]; $p=0.12$ using log-rank test)

\section{Primary outcome}

Mortality at day 28 was $18 \%$ (15 out of 84 patients) with NIV and 29\% (18 out of 62 patients) with high-flow nasal oxygen alone (difference, $-11 \%$ [95\% CI, -25 to
2]; $p=0.11$ using $X^{2}$ test and $p=0.12$ using log-rank test) (Table 2 and Fig. 1).

Among the 46 patients with hypercapnia at the onset of respiratory failure, mortality at day 28 was $3 \%$ (1 out of 33 patients) with NIV and $31 \%$ (4 out of 13 patients) 


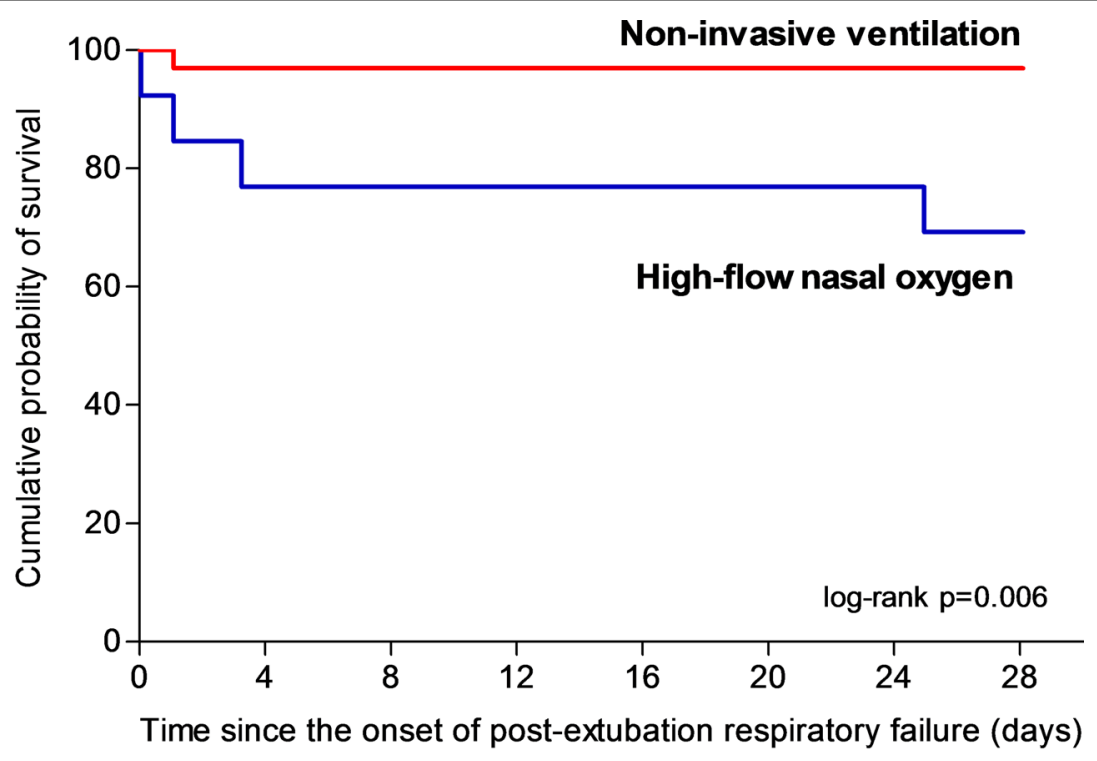

Number at risk

$\begin{array}{lllllllll}\text { High flow nasal oxygen } & 13 & 10 & 10 & 10 & 10 & 10 & 10 & 9 \\ \text { Non-invasive ventilation } & 33 & 32 & 32 & 32 & 32 & 32 & 32 & 32\end{array}$

Fig. 2 Kaplan-Meier analysis of time from the onset of post-extubation respiratory failure to death according to oxygenation strategy in the subgroup of patients with hypercapnia $\left(\mathrm{PaCO}_{2}>45 \mathrm{~mm} \mathrm{Hg}\right)$. Among the 46 patients with hypercapnia at the onset of respiratory failure mortality at day 28 was $3 \%$ ( 1 out of 33 patients) with NIV and 31\% (4 out of 13 patients) with high-flow nasal oxygen alone (difference, $-28 \%$ [95\% Cl, -54 to -6$] ; p=0.006$ using log-rank test)

with high-flow nasal oxygen alone (difference, $-28 \%$ [95\% CI, -54 to -6$] ; p=0.02$ using Fisher exact test and $p=0.006$ using log-rank test) (Fig. 2). Among the 77 patients without hypercapnia, mortality at day 28 was $23 \%$ (9 out of 40 patients) with NIV and 30\% (11 out of 37 patients) with high-flow nasal oxygen alone (difference, $-7 \%[95 \% \mathrm{CI},-26$ to 12$] ; p=0.47$ using $X^{2}$ test and $p=0.48$ using log-rank test) (Fig. 3).

\section{Secondary outcomes}

The proportion of patients reintubated $48 \mathrm{~h}$ after the onset of post-extubation respiratory failure was $44 \%$ (37 out of 84 patients) with NIV and 52\% (32 out of 62 patients) with high-flow nasal oxygen alone (difference, $-7 \%[95 \% \mathrm{CI},-23 \%$ to $9 \%] ; p=0.37$ using $x^{2}$ test and $p=0.21$ using log-rank test) (Table 2 and Fig. 4). The interval between the onset of respiratory failure and reintubation did not significantly differ between groups: $5.1 \mathrm{~h}$ in median [IQR 1.8-18.0] in the NIV group and $3 \mathrm{~h}$ [IQR $1.3-10.5]$ in the high-flow nasal oxygen group $(p=0.17)$ (Table 2).

The reintubation rate in ICU was significantly lower in patients with hypercapnia than in those without hypercapnia: 37\% (17 out of 46 patients) versus 57\% (44 out of

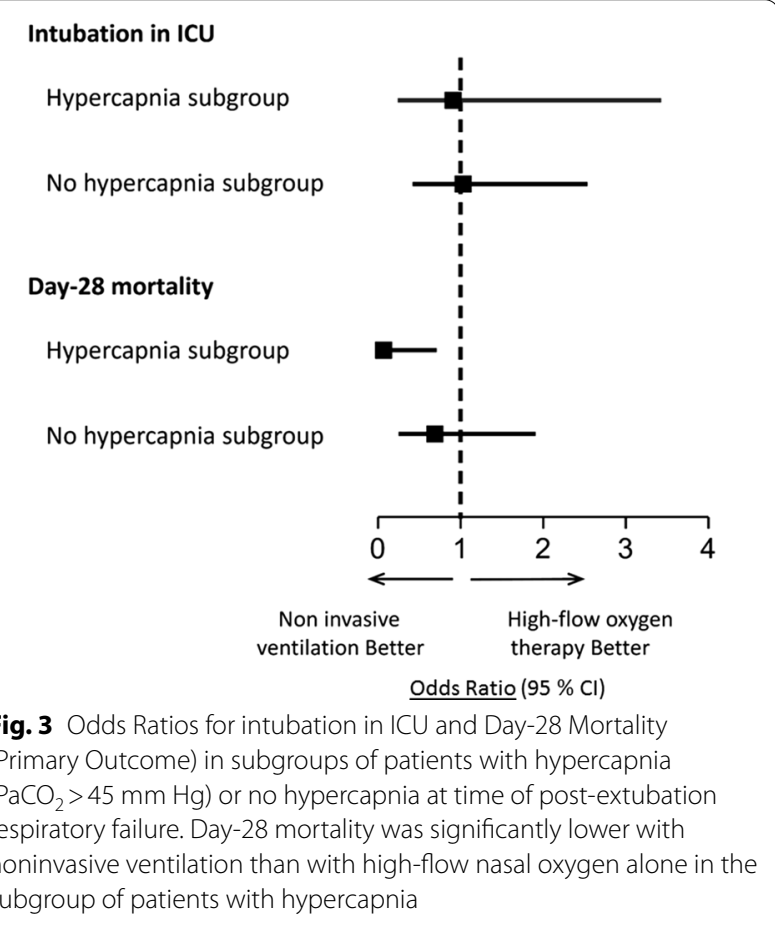




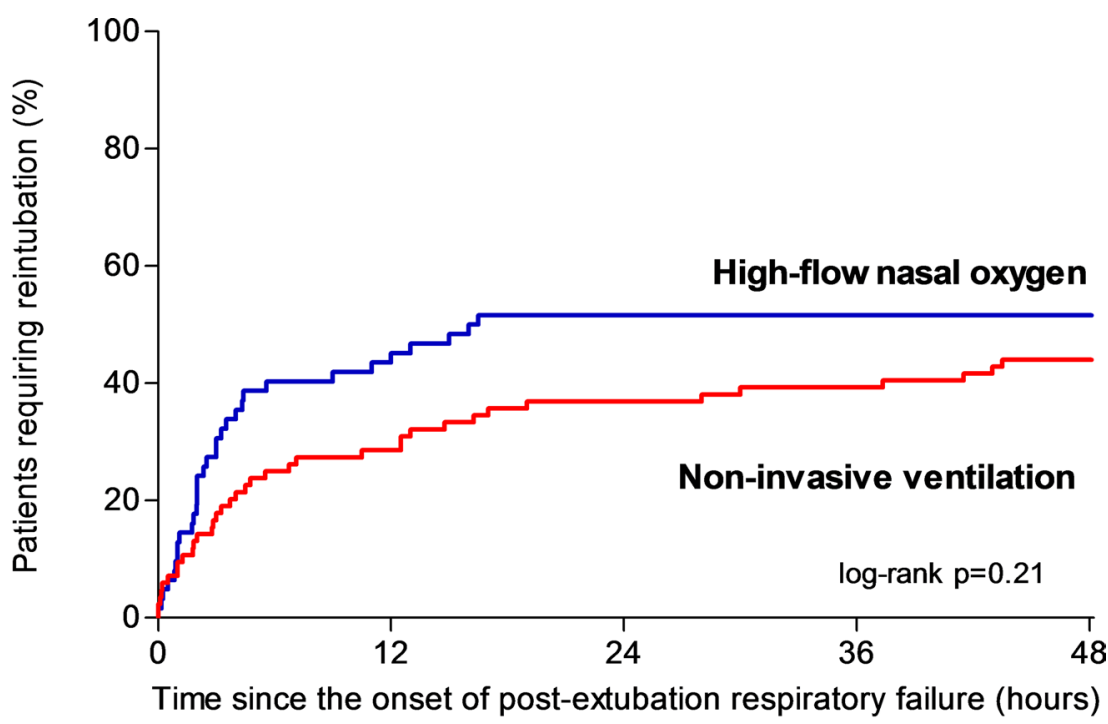

Number at risk

High flow nasal oxygen

Non-invasive ventilation
62

84
34

60
30

53
30

51
30

47

Fig. 4 Kaplan-Meier analysis of time from the onset of post-extubation respiratory failure to reintubation according to oxygenation strategy. Reintubation rates did not significantly differ between patients treated with non-invasive ventilation (red bars) and those treated with high-flow nasal oxygen alone (blue bars). The reintubation rate within the first $48 \mathrm{~h}$ after the onset of post-extubation respiratory failure was $44 \%$ (37 out of 84 patients) with NIV and $52 \%$ (32 out of 62 patients) with high-flow nasal oxygen alone (difference, $-7 \%$ [95\% Cl, $-23 \%$ to $9 \%$; $p=0.21$ using log-rank test)

77 patients), $p=0.03$. Among the 46 patients with hypercapnia at the onset of respiratory failure, reintubation rates were $38 \%$ ( 5 out of 13 patients) with high-flow nasal oxygen alone versus $36 \%$ (12 out of 33 patients) with NIV $(p=0.89)$. Patients who required reintubation in ICU were younger, had lower body-mass index and were more likely to have abundant secretions than those who did not require reintubation. At time of respiratory failure, they had a higher heart rate, were less likely to have clinical signs suggesting respiratory distress and less frequently had hypercapnia (Table 3). After multivariable analysis, hypercapnia was the only variable significantly associated with not being reintubated. The probability of reintubation was 2.27 times higher (95\% CI, 1.05 to 4.76 ; $p=0.04$ ) in patients without hypercapnia as compared to patients with hypercapnia.

Patients who died in the ICU were less likely to exhibit clinical signs suggesting respiratory distress and had lower diastolic arterial blood pressure than those who were discharged alive from the ICU (Additional File 1).

\section{Discussion}

In this post-hoc analysis of a randomized controlled trial focusing on patients who developed postextubation respiratory failure, mortality rates at day 28 did not differ between patients treated with NIV alternating with highflow nasal oxygen and those treated with high-flow nasal oxygen alone. In the subgroup of patients with hypercapnia, mortality rate was significantly lower with NIV than with high-flow nasal oxygen alone. Patients with hypercapnia had a lower risk of reintubation than the others, regardless of the oxygenation strategy.

\section{Use of NIV to treat post-extubation respiratory failure}

Few studies have assessed NIV in treatment of postextubation respiratory failure. The first clinical trial was published in 2002 and included 81 patients with postextubation respiratory failure randomly assigned to receive NIV or standard oxygen [19]. Reintubation rates were similar in the 2 groups (around 70\%) and mortality rates in the ICU did not significantly differ (15\% with NIV vs. $24 \%$ with standard oxygen, $p=0.34$ ). In 2004, contrary to all expectations, another clinical trial including 221 patients with post-extubation respiratory failure showed that patients treated by NIV may have an 
Table 3 Comparison between patients with post-extubation respiratory failure who required reintubation in ICU and those who were successfully treated without reintubation

\begin{tabular}{|c|c|c|c|}
\hline & No reintubation $(n=71)$ & Reintubation $(n=75)$ & $P$ value \\
\hline \multicolumn{4}{|l|}{ Characteristics of the patients at admission } \\
\hline Age, years & $72 \pm 9$ & $69 \pm 9$ & 0.049 \\
\hline Male sex, n (\%) & $40(56 \%)$ & $53(71 \%)$ & 0.07 \\
\hline Body-mass index, $\mathrm{kg} / \mathrm{m}^{2}$ & $30 \pm 8$ & $27 \pm 6$ & 0.02 \\
\hline Obesity, n (\%) & $30(43 \%)$ & $20(27 \%)$ & 0.04 \\
\hline SAPS II at admission, points & $58 \pm 18$ & $57 \pm 18$ & 0.86 \\
\hline Underlying chronic cardiac disease, n (\%) & $33(46 \%)$ & $32(43 \%)$ & 0.64 \\
\hline Underlying chronic lung disease, n (\%) & $29(41 \%)$ & $28(37 \%)$ & 0.66 \\
\hline Acute respiratory failure as reason for intubation, $\mathrm{n}(\%)$ & $43(61 \%)$ & $46(61 \%)$ & 0.92 \\
\hline \multicolumn{4}{|l|}{ Characteristics of the patients the day of extubation } \\
\hline SOFA score, points & $4.1 \pm 2.8$ & $4.8 \pm 2.7$ & 0.11 \\
\hline Duration of mechanical ventilation, median (IQR), days & $6[3-13]$ & $6[3-13]$ & 0.85 \\
\hline Weaning difficulty, n (\%) & & & 0.20 \\
\hline Simple weaning & $36(51 \%)$ & $49(65 \%)$ & \\
\hline Difficult or prolonged weaning & $35(49 \%)$ & $26(35 \%)$ & \\
\hline Ineffective cough, $\mathrm{n} / \mathrm{n}$ total (\%) & $25 / 67(37 \%)$ & $21 / 73(29 \%)$ & 0.28 \\
\hline Abundant secretions, n/n total (\%) & $24 / 68(35 \%)$ & $38 / 72(53 \%)$ & 0.04 \\
\hline Administration of steroids before extubation, $\mathrm{n}(\%)$ & $12(17 \%)$ & $5(7 \%)$ & 0.05 \\
\hline Prophylactic NIV after extubation, n (\%) & $32(45 \%)$ & $31(41 \%)$ & 0.65 \\
\hline \multicolumn{4}{|l|}{ Characteristics at time of ARF } \\
\hline Interval between extubation and respiratory failure, hours & $20[5-47]$ & $22[4-57]$ & 0.89 \\
\hline Systolic arterial pressure, $\mathrm{mm} \mathrm{Hg}$ & $135 \pm 25$ & $136 \pm 24$ & 0.67 \\
\hline Diastolic arterial pressure, $\mathrm{mm} \mathrm{Hg}$ & $66 \pm 14$ & $67 \pm 15$ & 0.94 \\
\hline Heart rate, beats/min & $82 \pm 33$ & $95 \pm 30$ & 0.01 \\
\hline Respiratory rate, breaths/min & $39 \pm 25$ & $35 \pm 22$ & 0.38 \\
\hline Clinical signs suggesting respiratory distress, n (\%) & $38(54 \%)$ & $15(20 \%)$ & $<0.001$ \\
\hline $\mathrm{SpO}_{2}, \%$ & $95 \pm 4$ & $94 \pm 7$ & 0.47 \\
\hline $\mathrm{PaO}_{2}, \mathrm{~mm} \mathrm{Hg}$ & $83 \pm 26$ & $80 \pm 36$ & 0.59 \\
\hline $\mathrm{PaO}_{2} / \mathrm{FiO}_{2}, \mathrm{~mm} \mathrm{Hg}$ & $196 \pm 76$ & $175 \pm 72$ & 0.18 \\
\hline $\mathrm{pH}$, units & $7,42 \pm 0,08$ & $7,44 \pm 0,09$ & 0.38 \\
\hline $\mathrm{PaCO}_{2}, \mathrm{~mm} \mathrm{Hg}$ & $47 \pm 13$ & $43 \pm 15$ & 0.09 \\
\hline Hypercapnia $\left(\mathrm{PaCO}_{2}>45 \mathrm{~mm} \mathrm{Hg}\right), \mathrm{n} / \mathrm{n}$ total (\%) & $29 / 62(47 \%)$ & $17 / 61(28 \%)$ & 0.03 \\
\hline \multicolumn{4}{|l|}{ Treatment of respiratory failure } \\
\hline Use of curative non-invasive ventilation, n (\%) & $44(61 \%)$ & $40(53 \%)$ & 0.29 \\
\hline Duration of administered treatment, hours & $57[28-86]$ & $5[2-16]$ & $<0.001$ \\
\hline Duration of curative high-flow nasal oxygen hours & $38[16-72]$ & $3[1-10]$ & $<0.001$ \\
\hline Duration of curative NIV, hours & $10[0-27]$ & $2[0-7]$ & 0.002 \\
\hline
\end{tabular}

$P$ values indicated in bold were considered statistically significant $(P<0.05)$

Continuous variables are given in mean \pm standard deviation or median [interquartile range, IQR 25th-75th percentiles] according to their distribution NIV = Non-invasive ventilation; SAPS = Simplified Acute Physiology Score

Values are given as mean \pm standard deviation or median [interquartile range, 25th-75th percentiles]

Weaning difficulty was defined as following: simple weaning included patients extubated after success of the initial spontaneous breathing trial, difficult weaning included patients who failed the initial spontaneous breathing trial and were extubated within the 7 following days, and prolonged weaning included patients extubated more than 7 days after the initial spontaneous breathing trial

increased risk of death as compared with standard oxygen [10]. Whereas reintubation rates were exactly the same between the 2 groups (48\%), mortality rate in ICU was higher in the NIV group than in the standard oxygen group ( $25 \%$ vs. $14 \%, p=0.048)$. In this study, patients treated with NIV were reintubated much later than those treated with standard oxygen $(12 \mathrm{~h}$ in median vs. $2 \mathrm{~h}$ after the onset of respiratory failure), suggesting that NIV may 
worsen outcome by delaying reintubation. A meta-analysis performed in 2014 on these two studies indicated no benefit of NIV compared with standard oxygen [20]. No further large-scale clinical trial has been performed after these 2 studies and thereby, the most recent international clinical practice guidelines suggest that NIV should not be used in the treatment of patients with established post-extubation respiratory failure [11]. However, the experts have pointed out that both studies included few patients with chronic obstructive pulmonary disease (around 10\%), so this recommendation may not apply to patients with underlying chronic lung disease who experience post-extubation respiratory failure, and that further studies are needed.

Unlike the clinical trial above-mentioned [10], we did not observe an increased risk of death in patients treated with NIV as compared with high-flow nasal oxygen. By contrast, we found that hypercapnic patients treated with NIV had even lower mortality than those treated with high-flow nasal oxygen alone. However, nearly $40 \%$ of the patients included in our study had underlying chronic lung disease compared to only $12 \%$ in the previous trial [10], and NIV may be particularly effective in this population. Moreover, the interval between NIV initiation and reintubation was markedly shorter in our study $(5 \mathrm{~h}$ in median) than in theirs (12 h), and may explain that NIV was not associated with an increased risk of death. In our study, predefined criteria for intubation were precisely defined in order to minimize the risk of delayed intubation, and this may have helped to avoid potential deleterious effects of NIV in this setting. Furthermore, unlike previous studies [10,19], all participating centers to our trial had extensive experience in NIV. Lastly, we used NIV alternately with high flow nasal oxygen and not NIV alone, which may have prolonged the beneficial effects of NIV during NIV breaks. However, all patients received high-flow nasal oxygen and NIV was the only additional treatment in the interventional group.

We found that patients with hypercapnia had a lower risk of reintubation than the others, regardless of the oxygenation strategy used. After multivariable analysis, hypercapnia at the onset of respiratory failure was the only factor independently associated with non-reintubation. These findings are in keeping with literature showing that patients with acute hypercapnic respiratory failure have lower intubation rates than non-hypercapnic patients $[11,21]$. However, reintubation rates did not differ between patients treated with NIV and those treated with high-flow nasal oxygen alone, even in case of hypercapnia. Several physiological studies have shown that high-flow nasal oxygen decreased post-extubation respiratory drive and may help to reduce work of breathing and $\mathrm{PCO}_{2}$ almost as effectively as NIV [22-24]. Consequently, these two oxygenation strategies could have similar efficacy to reverse hypercapnia and to avoid reintubation in this setting. Nevertheless, hypercapnic patients treated with NIV had lower mortality than those treated with high-flow nasal oxygen alone. It could be hypothesized that NIV may promote alveolar recruitment and reopening of atelectasis [25], improve clearance of tracheal secretions in case of weak cough [26], increase cardiac output and help treatment of cardiogenic pulmonary edema [27], and prevent apneas by delivering positive pressure [28]. Although this is an exploratory outcome focusing on a small-scale sample of patients, NIV use did not seem to have deleterious effects in this setting.

\section{Limitations}

The main limitation of this study is the post-hoc nature of the analysis. However, reintubation and mortality rates observed in our study ( $51 \%$ and $21 \%$, respectively) are almost exactly the same as those reported in the last clinical trial ( $48 \%$ and $21 \%$, respectively) [10]. Reintubation rates were similar even though our patients were treated with high-flow nasal oxygen and not with standard oxygen as in previous trials [10, 19]. However, we only included patients at high-risk of extubation failure, which may explain why reintubation rates were not lower, despite a potentially more effective oxygenation strategy. Concerning the reference treatment, a recent guideline panel made a conditional recommendation for the use of high-flow nasal oxygen following extubation (moderate certainty) [29].

A major limitation is that the choice of oxygenation strategy was left to the physician's discretion. Characteristics of the patients were similar between the NIV group and the high-flow nasal oxygen group aside from the fact that NIV was more frequently used in case of hypercapnia, situation in which NIV is associated with high success rates [13], and in patients who had already received NIV as a preventive measure before the onset of respiratory failure. This could be explained by the fact that it is easier to continue an oxygenation strategy already in place than to initiate a new one, even though NIV is associated with particularly low success rates in this situation. Indeed, reintubation rates exceeding $70 \%$ have been when NIV is used as rescue therapy to treat patients who already received preventive NIV [7, 8]. Despite this potential imbalance between groups, we did not find worse outcomes with NIV than with high-flow oxygen alone and we even report a decreased risk of death in patients with hypercapnia. 


\section{Clinical implications}

Although the most recent international clinical practice guidelines suggest that NIV should not be used in the treatment of patients with post-extubation respiratory failure [11], our findings confirm that this oxygenation strategy is routinely used as rescue therapy to avoid reintubation in this setting. Indeed, recently published several large-scale randomized controlled trials have reported that around $30-40 \%$ of patients with postextubation respiratory failure were treated with NIV [1, 2]. That could be explained by the fact that several studies have reported that NIV may help to avoid reintubation, especially in hypercapnic patients with underlying chronic lung disease $[7,8,12]$. These findings suggest that a large-scale randomized controlled trial should be conducted to better specify the most effective oxygenation strategy to treat established post-extubation respiratory failure in ICUs and potentially change clinical practice guidelines.

\section{Conclusion}

In patients who experienced post-extubation respiratory failure, NIV alternating with high-high-flow nasal oxygen did not increase the risk of death in ICU as compared to high-flow nasal oxygen alone. Patients with hypercapnia at the onset of respiratory failure had lower reintubation rates than the others.

\section{Supplementary Information}

The online version contains supplementary material available at https://doi. org/10.1186/s13054-021-03621-6.

Additional file 1. Comparison between patients who were discharged alive from ICU and those who died in ICUs after post-extubation respiratory failure.

\section{Acknowledgements}

We thank Jeffrey Arsham (CHU de Poitiers, Poitiers, France) for reviewing and editing the original English-language manuscript.

\section{HIGH-WEAN Study Group (etude.tipex@chu-poitiers.fr)}

Florence Boissier (Centre Hospitalier Universitaire de Poitiers, Médecine Intensive Réanimation, Poitiers), Delphine Chatellier (Centre Hospitalier Universitaire de Poitiers, Médecine Intensive Réanimation, Poitiers), Céline Deletage (Centre Hospitalier Universitaire de Poitiers, Médecine Intensive Réanimation, Poitiers), Carole Guignon (Centre Hospitalier Universitaire de Poitiers, Médecine Intensive Réanimation, Poitiers), Florent Joly (Centre Hospitalier Universitaire de Poitiers, Médecine Intensive Réanimation, Poitiers), Morgane Olivry (Centre Hospitalier Universitaire de Poitiers, Médecine Intensive Réanimation, Poitiers), Anne Veinstein (Centre Hospitalier Universitaire de Poitiers, Médecine Intensive Réanimation, Poitiers), Dalila Benzekri-Lefevre (Groupe Hospitalier Régional d'Orléans, Médecine Intensive Réanimation, Orléans), Thierry Boulain (Groupe Hospitalier Régional d'Orléans, Médecine Intensive Réanimation, Orléans), Grégoire Muller (Groupe Hospitalier Régional d'Orléans, Médecine Intensive Réanimation, Orléans), Yves Le Tulzo (Centre Hospitalier Universitaire de Rennes, Hôpital Ponchaillou, Service des Maladies Infectieuses et Réanimation Médicale, Rennes), Jean-Marc Tadié (Centre Hospitalier Universitaire de Rennes, Hôpital Ponchaillou, Service des Maladies Infectieuses et Réanimation Médicale, Rennes), Adel Maamar (Centre Hospitalier Universitaire de Rennes,
Hôpital Ponchaillou, Service des Maladies Infectieuses et Réanimation Médicale, Rennes), Suela Demiri (Groupe Hospitalier Pitié-Salpêtrière Charles Foix, Service de Pneumologie et Réanimation Médicale, AP-HP, Paris), Julien Mayaux (Groupe Hospitalier Pitié-Salpêtrière Charles Foix, Service de Pneumologie et Réanimation Médicale, Paris), Alexandre Demoule (Groupe Hospitalier PitiéSalpêtrière Charles Foix, Service de Pneumologie et Réanimation Médicale, Paris), Lila Bouadma (Hôpital Bichat-Claude Bernard, Médecine Intensive Réanimation, Paris), Claire Dupuis (Hôpital Bichat-Claude Bernard, Médecine Intensive Réanimation, Paris), Pierre Asfar (Centre Hospitalier Universitaire d’Angers, Département de Médecine Intensive Réanimation, Angers), Marc Pierrot (Centre Hospitalier Universitaire d’Angers, Département de Médecine Intensive Réanimation, Angers), Gaëtan Béduneau (Centre Hospitalier Universitaire de Rouen, Hôpital Charles Nicolle, Département de Réanimation Médicale, Rouen), Déborah Boyer (Centre Hospitalier Universitaire de Rouen, Hôpital Charles Nicolle, Département de Réanimation Médicale, Rouen), Benjamin Delmas (Centre Hospitalier Universitaire Félix Guyon, Service de Réanimation Polyvalente, Saint Denis de la Réunion), Bérénice Puech (Centre Hospitalier Universitaire Félix Guyon, Service de Réanimation Polyvalente, Saint Denis de la Réunion), Konstantinos Bachoumas (Centre Hospitalier Universitaire de Clermont-Ferrand, Hôpital Gabriel Montpied, Clermont-Ferrand), Edouard Soum (Centre Hospitalier Universitaire de Clermont-Ferrand, Hôpital Gabriel Montpied, Clermont-Ferrand), Séverin Cabasson (Centre Hospitalier de La Rochelle, Service de Réanimation, La Rochelle), Marie-Anne Hoppe (Centre Hospitalier de La Rochelle, Service de Réanimation, La Rochelle), Saad Nseir (Centre Hospitalier Universitaire de Lille, Center de Réanimation, Lille), Olivier Pouly (Centre Hospitalier Universitaire de Lille, Center de Réanimation, Lille), Gaël Bourdin (Hôpital Saint-Joseph Saint-Luc, Réanimation Polyvalente, Lyon), Sylvène Rosselli (Hôpital Saint-Joseph Saint-Luc, Réanimation Polyvalente, Lyon), Anthony Le Meur (Centre Hospitalier Universitaire de Nantes, Médecine Intensive Réanimation, Nantes), Charlotte Garret (Centre Hospitalier Universitaire de Nantes, Médecine Intensive Réanimation, Nantes), Maelle Martin (Centre Hospitalier Universitaire de Nantes, Médecine Intensive Réanimation, Nantes), Guillaume Berquier (Hôpital Louis Mourier, Réanimation Médico-Chirurgicale, Colombes) Abirami Thiagarajah (Hôpital Louis Mourier, Réanimation Médico-Chirurgicale, Colombes), Guillaume Carteaux (Hôpitaux Universitaires Henri Mondor, Service de Réanimation Médicale, Créteil), Armand MekontsoDessap (Hôpitaux Universitaires Henri Mondor, Service de Réanimation Médicale, Créteil), Antoine Poidevin (Groupe Hospitalier Régional Mulhouse Sud Alsace, site Emile Muller, Service de Réanimation Médicale, Mulhouse), Anne-Florence Dureau (Groupe Hospitalier Régional Mulhouse Sud Alsace, site Emile Muller, Service de Réanimation Médicale, Mulhouse), Marie-Ange Azais (Centre Hospitalier Départemental de Vendée, Service de Médecine Intensive Réanimation, La Roche Sur Yon), Gwenhaël Colin (Centre Hospitalier Départemental de Vendée, Service de Médecine Intensive Réanimation, La Roche Sur Yon), Emmanuelle Mercier (Centre Hospitalier Régional Universitaire de Tours, Médecine Intensive Réanimation, Tours), Marlène Morisseau (Centre Hospitalier Régional Universitaire de Tours, Médecine Intensive Réanimation, Tours), Caroline Sabatier (Centre Hospitalier de Pau, Service de Réanimation, Pau), Walter Picard (Centre Hospitalier de Pau, Service de Réanimation, Pau), Marc Gainnier (CHU La Timone 2, Médecine Intensive Réanimation, Marseille), Thi-My-Hue Nguyen (Centre Hospitalier Henri Mondor d'Aurillac, Service de Réanimation, Aurillac), Gwenaël Prat (Centre Hospitalier Universitaire de Brest, Médecine Intensive Réanimation, Brest), Carole Schwebel (Centre Hospitalier Universitaire Grenoble Alpes, Médecine Intensive Réanimation, Grenoble), Matthieu Buscot (Centre Hospitalier Universitaire de Nice, Réanimation Médicale Archet 1, Université Cote d'Azur, Nice).

\section{Authors' contributions}

AWT designed the study and wrote the manuscript. SR provided substantial contributions to the conception and design of the study, and performed statistical analysis. All authors contributed to drafting of the work, revising it critically for important intellectual content and approved the final version of the manuscript. All authors give their agreement to be accountable for all aspects of the work, and ensure the accuracy and integrity of any part of the work. A.W.T. is guarantor of the paper, taking responsibility for the integrity of the work as a whole, from inception to published article. All authors read and approved the final manuscript.

\section{Funding}

The study was conducted with the support of the "Programme Hospitalier de Recherche Clinique National 2015"from the French Ministry of Health (Grant 
Number 15-0060). The firm Fisher \& Paykel provided to all the participating centers the high-flow nasal oxygen equipment and masks for noninvasive ventilation but has no other involvement in the study.

\section{Availability of data and materials}

The datasets used and/or analysed during the current study are available from the corresponding author on reasonable request.

\section{Declarations}

\section{Ethics approval}

The study has been approved by the central ethics committee (Ethics Committee Ouest III, Poitiers, France) with the registration number 2016-A01078-43 (06 September 2016).

\section{Consent for publication}

Written informed consent was obtained from all patients or next of kin before inclusion. According to French law, this post-hoc analysis did not require further ethics approval.

\section{Competing interests}

DrThille reported receiving grants from the French Ministry of Health and personal fees and nonfinancial support from Fisher \& Paykel Healthcare during the conduct of the study and personal fees from Maquet-Getinge, GE Healthcare, and Covidien outside the submitted work. Dr Sonneville reported receiving grants from the French Ministry of Health, the European Society of Intensive Care Medicine, and the French Society of Intensive Care Medicine and personal fees from Baxter outside the submitted work. Dr Beloncle reported receiving personal fees from Lowenstein Medical and nonfinancial support from GE Healthcare, Getinge Group, and Covidien outside the submitted work. Dr Girault reported receiving grants, personal fees, and nonfinancial support from Fisher \& Paykel Healthcare during the conduct of the study and grants and nonfinancial support from ResMed outside the submitted work. Dr Ricard reported receiving travel and accommodation expenses from Fisher \& Paykel Healthcare outside the submitted work. Dr Ehrmann reported receiving grants, nonfinancial support, and other funding from Fisher \& Paykel Healthcare during the conduct of the study; grants, personal fees, nonfinancial support, and other funding from Aerogen; grants from Hamilton; personal fees from La Diffusion Technique Française; and personal fees from Baxter outside the submitted work. Dr Terzi reported receiving personal fees from Boehringer Ingelheim and Pfizer outside the submitted work. Dr Demoule reported receiving personal fees from Medtronic, Baxter, Hamilton, and Getinge; grants, personal fees, and nonfinancial support from Philips and Lungpacer; personal fees and nonfinancial support from Fisher \& Paykel Healthcare; and grants from the French Ministry of Health and Respinor outside the submitted work. Dr Frat reported receiving personal fees and nonfinancial support from Fisher \& Paykel Healthcare during the conduct of the study and personal fees and nonfinancial support from SOS Oxygen outside the submitted work. No other disclosures were reported.

\section{Author details}

${ }^{1}$ Centre Hospitalier Universitaire de Poitiers, Service de Médecine Intensive Réanimation, Médecine Intensive Réanimation, 2 rue la Milétrie, 86021 Poitiers Cedex, France. ${ }^{2}$ Centre d'Investigation Clinique 1402 ALIVE Research Group, University of Poitiers, Poitiers, France. ${ }^{3}$ Centre Hospitalier Régional d'Orléans,

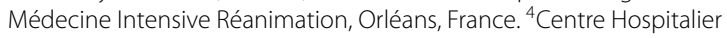
Universitaire de Rennes, Service des Maladies Infectieuses et Réanimation Médicale, Hôpital Ponchaillou, Rennes, France. ${ }^{5}$ Hôpital Pitié-Salpêtrière, Service de Pneumologie, Médecine Intensive et Réanimation (Département R3S), AP-HP 6 - Sorbonne, INSERM, UMRS1158 Neurophysiologie Respiratoire Expérimentale et Clinique, Sorbonne Université, Paris, France. ${ }^{6}$ Hôpital Bichat - Claude Bernard, Médecine Intensive Réanimation, AP-HP, Université Paris Diderot, Paris, France. ${ }^{7}$ Centre Hospitalier Universitaire d'Angers, Département de Médecine Intensive Réanimation, Université d'Angers, Angers, France. ${ }^{8}$ Centre Hospitalier Universitaire de Rouen, Hôpital Charles Nicolle, Département de Réanimation Médicale, Normandie Université, UNIROUEN, EA3830-GRHV, Institute for Research and Innovation in Biomedicine (IRIB), Rouen, France. ${ }^{9}$ Centre Hospitalier Universitaire Félix Guyon, Service de Réanimation Polyvalente, Saint Denis de la Réunion, France. ${ }^{10} \mathrm{Centre} \mathrm{Hospitalier}$ Universitaire de Clermont-Ferrand, Hôpital Gabriel Montpied, Service de
Réanimation Médicale, Clermont-Ferrand, France. ${ }^{11}$ Centre Hospitalier de la Rochelle, Service de Réanimation, La Rochelle, France. ${ }^{12}$ Centre de Réanimation, Centre Hospitalier Universitaire de Lille, Université de Lille, Lille, France. ${ }^{13}$ Hôpital Saint-Joseph Saint-Luc, Réanimation Polyvalente, Lyon, France.

${ }^{14}$ Médecine Intensive Réanimation, Centre Hospitalier Universitaire de Nantes, Nantes, France. ${ }^{15}$ Hôpital Louis Mourier, Réanimation Médico-Chirurgicale, AP-HP, INSERM, UMR IAME 1137, Sorbonne Paris Cité, Université Paris Diderot, Colombes, France. ${ }^{16}$ Hôpitaux Universitaires Henri Mondor, Service de Réanimation Médicale DHU A-TVB, AP-HP, Créteil, France. ${ }^{17}$ Groupe Hospitalier Régional Mulhouse Sud Alsace, Service de Réanimation Médicale, Site Emile Muller, Mulhouse, France. ${ }^{18}$ Service de Médecine Intensive Réanimation, Centre Hospitalier Départemental de Vendée, La Roche Sur Yon, France. ${ }^{19}$ Centre Hospitalier Régional Universitaire de Tours, Médecine Intensive Réanimation, CIC 1415, Réseau CRICS-Trigger SEP, Centre d'étude des pathologies respiratoires, INSERM U1 100, Université de Tours, Tours, France. ${ }^{20}$ Centre Hospitalier de Pau, Service de Réanimation, Pau, France. ${ }^{21}$ Centre Hospitalier Universitaire La Timone 2, Médecine Intensive Réanimation, Réanimation des Urgences, Aix-Marseille Université, Marseille, France. ${ }^{22}$ Service de Réanimation, Centre Hospitalier Henri Mondor d'Aurillac, Aurillac, France. ${ }^{23}$ Centre Hospitalier Universitaire de Brest, Médecine Intensive Réanimation, Brest, France. ${ }^{24}$ Centre Hospitalier Universitaire Grenoble Alpes, Médecine Intensive Réanimation, INSERMU1042, HP2, Université Grenoble-Alpes, Grenoble, France. ${ }^{25}$ Centre Hospitalier Universitaire de Nice, Médecine Intensive Réanimation, Archet 1 , UR2CA, Université Cote d'Azur, Nice, France. ${ }^{26}$ Centre Hospitalier de Versailles, Service de Réanimation Médico-Chirurgicale, Le Chesnay, France.

Received: 3 February 2021 Accepted: 31 May 2021

Published online: 28 June 2021

\section{References}

1. Thille AW, Muller G, Gacouin A, Coudroy R, Decavele M, Sonneville R, Beloncle F, Girault C, Dangers L, Lautrette A, et al. Effect of postextubation high-flow nasal oxygen with noninvasive ventilation vs high-flow nasal oxygen alone on reintubation among patients at high risk of extubation failure: a randomized clinical trial. JAMA. 2019;322(15):1465-75.

2. Subira C, Hernandez G, Vazquez A, Rodriguez-Garcia R, Gonzalez-Castro A, Garcia C, Rubio O, Ventura L, Lopez A, de la Torre MC, et al. Effect of pressure support vs T-piece ventilation strategies during spontaneous breathing trials on successful extubation among patients receiving mechanical ventilation: a randomized clinical trial. JAMA. 2019;321(22):2175-82.

3. Epstein SK, Ciubotaru RL, Wong JB. Effect of failed extubation on the outcome of mechanical ventilation. Chest. 1997;112(1):186-92.

4. Frutos-Vivar F, Esteban A, Apezteguia C, Gonzalez M, Arabi Y, Restrepo MI, Gordo F, Santos C, Alhashemi JA, Perez F, et al. Outcome of reintubated patients after scheduled extubation. J Crit Care. 2011;26(5):502-9.

5. Thille AW, Richard J-CM, Brochard L. The decision to extubate in the intensive care unit. Am J Respir Crit Care Med. 2013;187(12):1294-302.

6. Nava S, Gregoretti C, Fanfulla F, Squadrone E, Grassi M, Carlucci A, Beltrame $F$, Navalesi P. Noninvasive ventilation to prevent respiratory failure after extubation in high-risk patients. Crit Care Med. 2005;33(1 1):2465-70.

7. Ferrer M, Valencia M, Nicolas JM, Bernadich O, Badia JR, Torres A. Early noninvasive ventilation averts extubation failure in patients at risk: a randomized trial. Am J Respir Crit Care Med. 2006;173(2):164-70.

8. Ferrer M, Sellares J, Valencia M, Carrillo A, Gonzalez G, Badia JR, Nicolas $J M$, Torres A. Non-invasive ventilation after extubation in hypercapnic patients with chronic respiratory disorders: randomised controlled trial. Lancet (London, England). 2009;374(9695):1082-8.

9. Vargas F, Clavel M, Sanchez-Verlan P, Garnier S, Boyer A, Bui HN, Clouzeau B, Sazio C, Kerchache A, Guisset O, et al. Intermittent noninvasive ventilation after extubation in patients with chronic respiratory disorders: a multicenter randomized controlled trial (VHYPER). Intensive Care Med. 2017;43(11):1626-36.

10. Esteban A, Frutos-Vivar F, Ferguson ND, Arabi Y, Apezteguia C, Gonzalez M, Epstein SK, Hill NS, Nava S, Soares MA, et al. Noninvasive positivepressure ventilation for respiratory failure after extubation. N Engl J Med. 2004;350(24):2452-60.

11. Rochwerg B, Brochard L, Elliott MW, Hess D, Hill NS, Nava S, Navalesi PMOTSC, Antonelli M, Brozek J, Conti G, et al. Official ERS/ATS clinical 
practice guidelines: noninvasive ventilation for acute respiratory failure. Eur Respir J. 2017;50(2):1602426.

12. Girault C, Bubenheim M, Abroug F, Diehl JL, Elatrous S, Beuret P, Richecoeur J, L'Her E, Hilbert G, Capellier G, et al. Noninvasive ventilation and weaning in patients with chronic hypercapnic respiratory failure: a randomized multicenter trial. Am J Respir Crit Care Med. 2011;184(6):672-9.

13. Hilbert G, Gruson D, Portel L, Gbikpi-Benissan G, Cardinaud JP. Noninvasive pressure support ventilation in COPD patients with postextubation hypercapnic respiratory insufficiency. Eur Respir J. 1998;11(6):1349-53.

14. Maggiore SM, Idone FA, Vaschetto R, Festa R, Cataldo A, Antonicelli F, Montini L, De Gaetano A, Navalesi P, Antonelli M. Nasal high-flow. versus Venturi mask oxygen therapy after extubation. Effects on oxygenation, comfort, and clinical outcome. Am J Respir Crit Care Med. 2014;190(3):282-8.

15. Hernandez G, Vaquero C, Gonzalez P, Subira C, Frutos-Vivar F, Rialp G, Laborda C, Colinas L, Cuena R, Fernandez R. Effect of postextubation high-flow nasal cannula vs conventional oxygen therapy on reintubation in low-risk patients: a randomized clinical trial. JAMA. 2016;315(13):1354-61.

16. Hernandez G, Vaquero C, Colinas L, Cuena R, Gonzalez P, Canabal A, Sanchez S, Rodriguez ML, Villasclaras A, Fernandez R. Effect of postextubation high-flow nasal cannula vs noninvasive ventilation on reintubation and postextubation respiratory failure in high-risk patients: a randomized clinical trial. JAMA. 2016;316(15):1565-74.

17. Frat JP, Thille AW, Mercat A, Girault C, Ragot S, Perbet S, Prat G, Boulain T, Morawiec E, Cottereau A, et al. High-flow oxygen through nasal cannula in acute hypoxemic respiratory failure. $N$ Engl I Med. 2015;372(23):2185-96.

18. Coudroy R, Frat JP, Girault C, Thille AW. Reliability of methods to estimate the fraction of inspired oxygen in patients with acute respiratory failure breathing through non-rebreather reservoir bag oxygen mask. Thorax. 2020;75(9):805-7.

19. Keenan SP, Powers C, McCormack DG, Block G. Noninvasive positivepressure ventilation for postextubation respiratory distress: a randomized controlled trial. JAMA. 2002;287(24):3238-44.

20. Lin C, Yu H, Fan H, Li Z. The efficacy of noninvasive ventilation in managing postextubation respiratory failure: a meta-analysis. Heart Lung J Crit Care. 2014:43(2):99-104.
21. Demoule A, Girou E, Richard JC, Taille S, Brochard L. Increased use of noninvasive ventilation in French intensive care units. Intensive Care Med. 2006:32(11):1747-55.

22. Di Mussi R, Spadaro S, Stripoli T, Volta CA, Trerotoli P, Pierucci P, Staffieri F, Bruno F, Camporota L, Grasso S. High-flow nasal cannula oxygen therapy decreases postextubation neuroventilatory drive and work of breathing in patients with chronic obstructive pulmonary disease. Crit Care (London, England). 2018;22(1):180

23. Pisani L, Fasano L, Corcione N, Comellini V, Musti MA, Brandao M, Bottone D, Calderini E, Navalesi P, Nava S. Change in pulmonary mechanics and the effect on breathing pattern of high flow oxygen therapy in stable hypercapnic COPD. Thorax. 2017;72(4):373-5.

24. Rittayamai N, Phuangchoei P, Tscheikuna J, Praphruetkit N, Brochard L. Effects of high-flow nasal cannula and non-invasive ventilation on inspiratory effort in hypercapnic patients with chronic obstructive pulmonary disease: a preliminary study. Ann Intensive Care. 2019;9(1):122.

25. L'Her E, Deye N, Lellouche F, Taille S, Demoule A, Fraticelli A, Mancebo J, Brochard L. Physiologic effects of noninvasive ventilation during acute lung injury. Am J Respir Crit Care Med. 2005;172(9):1112-8.

26. Duan J, Han X, Huang S, Bai L. Noninvasive ventilation for avoidance of reintubation in patients with various cough strength. Crit Care (London, England). 2016;20(1):316.

27. Lenique F, Habis M, Lofaso F, Dubois-Randé JL, Harf A, Brochard L. Ventilatory and hemodynamic effects of continuous positive airway pressure in left heart failure. Am J Respir Crit Care Med. 1997;155:500-5.

28. Marin JM, Soriano JB, Carrizo SJ, Boldova A, Celli BR. Outcomes in patients with chronic obstructive pulmonary disease and obstructive sleep apnea: the overlap syndrome. Am J Respir Crit Care Med. 2010;182(3):325-31.

29. Rochwerg B, Granton D, Wang DX, Helviz Y, Einav S, Frat JP, MekontsoDessap A, Schreiber A, Azoulay E, Mercat A, et al. High flow nasal cannula compared with conventional oxygen therapy for acute hypoxemic respiratory failure: a systematic review and meta-analysis. Intensive Care Med. 2019:45(5):563-72.

\section{Publisher's Note}

Springer Nature remains neutral with regard to jurisdictional claims in published maps and institutional affiliations.
Ready to submit your research? Choose BMC and benefit from:

- fast, convenient online submission

- thorough peer review by experienced researchers in your field

- rapid publication on acceptance

- support for research data, including large and complex data types

- gold Open Access which fosters wider collaboration and increased citations

- maximum visibility for your research: over $100 \mathrm{M}$ website views per year

At BMC, research is always in progress.

Learn more biomedcentral.com/submissions 